\title{
ЕТF КАК НОВЫЙ СПОСОБ ИНВЕСТИРОВАНИЯ НА МИРОВОМ РЫНКЕ ДРАГМЕТАЛЛОВ
}

\author{
(c) 2020 Бризицкая Анна Валентиновна \\ кандидат экономических наук, \\ доцент кафедры мировой экономики Школы экономики и менеджмента \\ Дальневосточный Федеральный Университет, Россия, Владивосток \\ Email: brizitskaya.av@dvfu.ru \\ (c) 2020 Дьяченко Юлия Констанстиновна \\ кандидат экономических наук, \\ доцент кафедры мировой экономики Школы экономики и менеджмента \\ Дальневосточный Федеральный Университет, Россия, Владивосток \\ Email: dyachenko.yuk@dvfu.ru
}

\section{() 2020 Якимова Вилена Анатольевна}

кандидат экономических наук, доцент кафедры финансов Амурский государственный университет, Россия, Благовещенск

E-mail: vilena_yakimova@mail.ru

Цель статьи - проанализировать сильные и слабые стороны ETF как нового способа инвестирования на мировом рынке драгметаллов. Особое внимание авторы уделили рассмотрению основных моментов, на которые следует обращать внимание инвестору, при покупке акций ЕTF, а именно: активам, лежащим в основе фонда; его доходности; ликвидности и расходам инвестора, связанным с комиссионными выплатами фонду на управление активами. Проведенное исследование позволило сделать вывод о том, что ETF представляют собой хорошую возможность для инвестора диверсифицировать свой портфель, однако предполагает наличие у него достаточных знаний и опыта, чтобы сделать правильный выбор.

Ключевые слова: ETF, инвестирование, рынок драгметаллов, золото, способы вложения денежных средств.

Мировые рынки драгоценных металлов, и в первую очередь рынок золота, являются одним из самых интересных объектов для инвестиций и профессиональных спекуляций, особенно при нестабильной политической и экономической обстановке: они обладают практически всеми качествами финансового инструмента, но в то же время остаются товаром, представляя собой особый тип финансовых активов. Драгоценные металлы как наличный, материальный актив не зависят от выполнения своих платежных обязательств никакими правительствами или корпорациями. Это особенно важно в современных условиях, когда большинство других объектов инвестиций представляют собой не имущество как таковое, а имущественные права, использование или реализация которых могут быть затруднены ввиду неплатежеспособности должника, ареста денежных средств или ценных бумаг на счетах, смены экономической политики какого-либо конкретного государства. Именно по этим причинам примерно четверть всех мировых запасов золота находится во владении правительств, центральных банков и других финансовых институтов как часть их международных резервов.

Существует несколько способов вложения денежных средств в драгоценные металлы (рисунок 1).

Относительно новым способом инвестирования на мировом рынке драгоценных металлов является вложение средств в ETF, основанных на драгметаллах. ETF (Exchange traded funds) биржевые фонды, разновидность коллективных инвестиций, представляют собой набор активов, лежащих в основе рыночного индекса. Этим активами могут быть подобранные по определенному принципу акции компаний, облигации, фьючерсные контракты на валюту, сырьевые товары, либо в случае с ETF на драгметаллы - 
Основные способы инвестирования на рынке драгоценных металлов

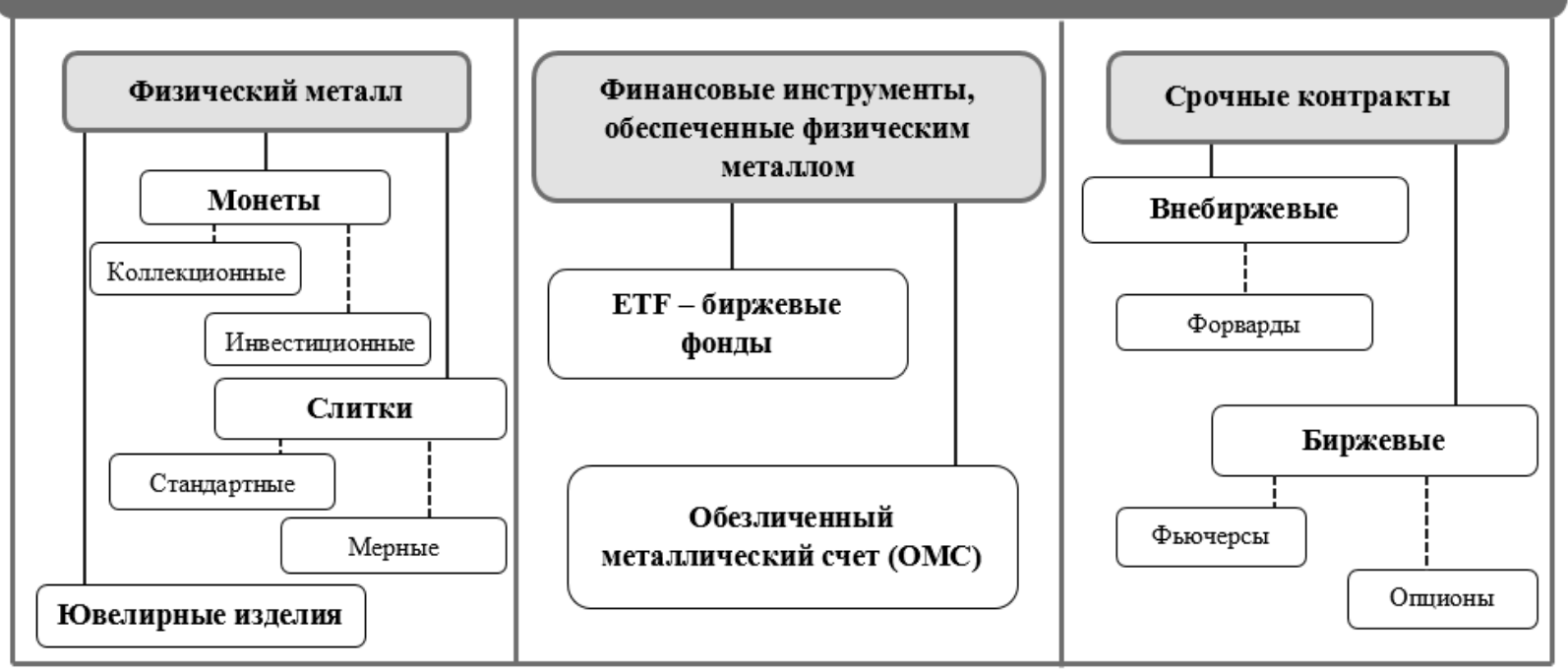

Рисунок 1. Основные способы инвестирования на мировом рынке драгоценных металлов Источник: составлено авторами

слитки драгоценных металлов. Под их залог выпускаются акции фонда, которые торгуются на бирже как обычные акции предприятий. По мере изменения стоимости активов, изменяются и показатели индексов, и цена ETF [3].

Не все металлические ETF фонды следуют за динамикой цен на соответствующий металл, управляющая компания может инвестировать средства не в один металл, а в корзину из нескольких драгоценных металлов, а также в акции добывающих компаний, или осуществлять спекулятивные операции покупки и продажи металла (на основе фьючерсов). Также есть ETF, совмещающие и слитки, и акции добывающих компаний. В таком случае стоимость паев ЕTF может расти, в то время как цена на металл падает и наоборот.

Выделим главные моменты, на которые следует обращать внимание инвестору, при покупке ETF:

1) актив: металл в слитках или игра на стоимости фьючерсов. ETF, использующие физическую поддержку металла, способны устранить проблемы контанго и бэквардации, характерных для фьючерсов, и защищены от сложности фьючерсных контрактов и опасностей, связанных с ними. Фьючерсы потенциально полезны для тех, кто хочет сделать ставку на краткосрочное изменение цены драгоценного металла, опытны и терпимы к рискам. ETF, основанные на фьючерсах, лучше не включать в долгосрочный порт- фель, и их должны использовать только те, кто способен внимательно следить за ситуацией на рынке.

2) доходность ETF - она также зависит от актива, находящегося в основе, и от отслеживаемого индекса. В случае физического металла доходность прямо зависит от цены на этот металл на рынке, что легко отслеживается и прогнозируется. Если же ЕTF использует фьючерсы, то в основе находится индекс, состоящий из фьючерсных контрактов на металл. Таких индексов очень много и важно различать их и понимать структуру и принцип формирования именно того индекса, который отслеживает выбранный ETF. Такие фонды могут быть очень прибыльными при правильном использовании, поэтому подходят только для опытных инвесторов или даже скорее для трейдеров.

3) расходы инвестора, связанные с комиссионными выплатами фонду на управление активами. Они складываются из прибыли фонда, его расходов на ведение деятельности, платы за хранение слитков в банках, стоимости услуг банков и биржи и др. Так, комиссия обычно располагается в пределах от 0,17\% до 2\%. Не стоит сразу выбирать то, что дешевле - возможно, фонд экономит на стоимости и надежности банка, где хранятся слитки, что может фатально сказаться на инвестициях. [1]

4) ликвидность. Многие специализированные аналитические сайты по инвестициям в ETF 
на драгоценные металлы публикуют текущую информацию о рейтингах риска и ликвидности данных фондов. Они подразделяются по следующим буквам: когда фонд имеет рейтинг от А до В - значит, следует покупать акции данного фонда, C - держать пока в портфеле, a D, E и F акции следует продавать. [2]

Рассмотрим, какие ETF существуют в мире и какие условия предлагают вкладчикам. Штаб-квартиры многих ETF на основе драгоценных металлов, в том числе старейших, располагаются в США, храня при этом активы в других странах, как Швейцария и Великобритания, поэтому рассмотрим ETF, которые торгуются на биржах в этой стране. В таблице 1 представлен список крупнейших фондов по драгоценным металлам.

Одни из самых старейших и известнейших ETF в мире - GLD и IAU. Базовые активы данных фондов состоят из золотых слитков, хранящихся в надежных хранилищах, поэтому можно ожидать, что цена этих ETF будет двигаться в шаге от спотовых цен на золото. Хотя базовые активы похожи и взаимозаменяемы и IAU проигрывает по ликвидности, комиссия на управление и хранение слитков IAU дешевле на 15 базисных пунктов и стоимость акции значительно ниже, что дает возможность вложения меньшего количества средств для частных инвесторов. IAU име- ет один из самых низких показателей расходов, что делает его надежным выбором для экономных инвесторов. Посоревноваться с IAU может относительно недавно сформированный GLDM (в 2018 г.) от той же структуры, которой принадлежит GLD. Это, фактически, аналог GLD, но торг производится меньшими по объему акциями и уровень комиссии в разы дешевле. [1]

От двух гигантов значительно отстает SGOL, также вкладывающийся в золотые слитки. Фонд содержит золотые слитки в безопасном хранилище в Швейцарии, которое проверяется дважды в год. Компания также публикует серийные номера слитков, что дает инвесторам гарантию соответствия объема акций запасам фонда и дополнительную безопасность в отношении статуса их инвестиций. Хотя SGOL не самый ликвидный способ получить доступ к золоту, он мог бы стать надежным выбором для инвесторов, стремящихся к большему спокойствию в отношении инвестиций в драгоценные металлы. Также комиссия SGOL и BAR являются самыми малыми на рынке ETF на основе драгоценных металлов.

Если рассматривать серебро с физической поддержкой, то стоит обратить внимание на SIVR и SLV. Они почти идентичны, хотя SLV взимает немного более высокий коэффициент расходов. PPLT является еще одним примером ETF с физической поддержкой акций драгоценными

Таблица 1. Список крупнейших ETF по драгоценным металлам (на основе принадлежащих активов)

\begin{tabular}{|c|c|c|c|c|c|c|c|}
\hline № & Тикер & Название ETF & Актив & $\begin{array}{c}\text { Всего } \\
\text { активов } \\
\text { (млн. } \\
\text { долл. } \\
\text { США) }\end{array}$ & $\begin{array}{l}\text { \% комис- } \\
\text { сии }\end{array}$ & $\begin{array}{c}\text { Цена за } \\
\text { акцию, } \\
\text { долл. } \\
\text { США }\end{array}$ & $\begin{array}{c}\text { Ликвид- } \\
\text { ность }\end{array}$ \\
\hline 1 & GLD & SPDR Gold Trust & золото в слитках & 33882,55 & 0,40 & 131,98 & $\mathrm{~A}+$ \\
\hline 2 & IAU & iShares Gold Trust & золото в слитках & 12805,98 & 0,25 & 13,39 & $\mathrm{~A}$ \\
\hline 3 & SLV & iShares Silver Trust & серебро в слитках & 4903,22 & 0,50 & 14,36 & $\mathrm{~A}$ \\
\hline 4 & SGOL & $\begin{array}{l}\text { Aberdeen Standard Physical } \\
\text { Swiss Gold Shares ETF }\end{array}$ & золото в слитках & 910,63 & 0,17 & 134,84 & A- \\
\hline 5 & GLDM & SPDR Gold MiniShares Trust & золото в слитках & 761,52 & 0,18 & 13,97 & $\mathrm{n} / \mathrm{a}$ \\
\hline 6 & PPLT & $\begin{array}{c}\text { Aberdeen Standard Platinum } \\
\text { Shares ETF }\end{array}$ & платина в слитках & 558,21 & 0,60 & 76,46 & $\mathrm{~B}+$ \\
\hline 7 & BAR & GraniteShares Gold Trust & золото в слитках & 534,11 & 0,17 & 13,95 & B- \\
\hline 8 & GLTR & $\begin{array}{c}\text { Aberdeen Standard Physical } \\
\text { Precious Metals Basket Shares } \\
\text { ETF }\end{array}$ & $\begin{array}{c}\text { корзина драго- } \\
\text { ценных металлов } \\
\text { (фьючерсы) }\end{array}$ & 375,49 & 0,60 & 67,43 & B \\
\hline 9 & SIVR & $\begin{array}{c}\text { Aberdeen Standard Physical } \\
\text { Silver Shares ETF }\end{array}$ & серебро в слитках & 337,04 & 0,30 & 14,88 & $\mathrm{~A}$ \\
\hline 10 & USLV & $\begin{array}{c}\text { VelocityShares 3x Long Silver } \\
\text { ETN }\end{array}$ & $\begin{array}{l}\text { серебро на фью- } \\
\text { черсной основе }\end{array}$ & 251,49 & 1,65 & 66,38 & A \\
\hline
\end{tabular}

Источник: [4] 
металлами. PPLT, первый зарегистрированный в США ETF, обеспеченный запасами физической платины, является не особо ликвидным активом, отстает от серебряных и золотых ЕTF и по объему, и по ликвидности.

GLTR использует уникальный подход к инвестированию в драгоценные металлы. Хотя многие фонды используют физический металл для более стабильных инвестиций, этот фонд сделал еще один шаг вперед и инвестировал в четыре отдельных драгоценных металла: золото, серебро, палладий и платину. Этот фонд, как и USLV, основан на фьючерсных контрактах, что делает его подверженным рискам контанго, бэквардации и другим проблемам, связанным с продуктами, обеспеченными фьючерсами. Инвесторы должны принять к сведению, что, хотя этот фонд предоставляет доступ к четырем отдельным металлам, на долю золота и серебра приходится более 85\% корзины этого фонда. [1]

В таблице 2 представлен рейтинг самых доходных ETF на драгоценные металлы за последние 5 лет. Наиболее выгодным фондом является PALL, так как палладий в последние годы стремительно набирает стоимость, что сказывается на основанном на нем фонде. Следующими, традиционно показывающие прирост, являются золотые ETF, в том числе крупнейшие GLD, IAU и SGOL. Из фьючерсных фондов прирост показал лишь UBG, остальные терпели убытки.
На основе проведенного анализа были выявлены основные преимущества и недостатки инвестирования в ЕTF. Преимущества инвестиций в драгоценный металл через покупку ETF:

- минимальный спред в сравнении с инвестициями через открытие ОМС;

- возможность маржинальной торговли на бирже, за счет которой в сочетании с наименьшим спредом можно извлечь прибыль даже при незначительном колебании курса;

- возможность быстро купить или продать паи фонда во время торговой сессии;

- онлайн доступ к котировкам, позволяющий гораздо быстрее среагировать на изменения курса актива (в то время как банк меняет курс обезличенного металла один или два раза в день);

- возможность выкупа и доставки физического металла;

- сведение издержек на инвестирование к минимуму, гарантирующее участникам более высокий доход, чем у других рыночных игроков. Это единственный подход к инвестированию в ценные бумаги, который может обеспечить такие результаты.

Недостатки способа:

- наличие комиссии на услуги фонда;

- возможность появления риска отказа поставки металла при условии, что количество выпускаемых акций, несмотря на заверения и

Таблица 2. Рейтинг самых доходных ЕTF на драгоценные металлы за последние 5 лет (2014-2019 гг.), в процентах

\begin{tabular}{|c|c|c|c|c|c|c|}
\hline No & Тикер & Название & Актив & Комиссия & 1 год & 5 лет \\
\hline 1 & PALL & $\begin{array}{c}\text { Aberdeen Standard Physical Palladium } \\
\text { Shares ETF }\end{array}$ & палладий в слитках & 0,6 & 54,26 & 76,72 \\
\hline 2 & IAU & iShares Gold Trust & золото в слитках & 0,25 & 6,05 & 5,02 \\
\hline 3 & SGOL & $\begin{array}{c}\text { Aberdeen Standard Physical Swiss } \\
\text { Gold Shares ETF }\end{array}$ & золото в слитках & 0,17 & 5,95 & 4,4 \\
\hline 4 & GLD & SPDR Gold Trust & золото в слитках & 0,4 & 5,87 & 4,26 \\
\hline 5 & OUNZ & Van Eck Merk Gold Trust & золото в слитках & 0,4 & 5,9 & 4,24 \\
\hline 6 & UBG & $\begin{array}{c}\text { E-TRACS UBS Bloomberg CMCI Gold } \\
\text { ETN }\end{array}$ & $\begin{array}{c}\text { золото на фьючерс- } \\
\text { ной основе }\end{array}$ & 0,3 & 2,84 & 2,39 \\
\hline 7 & DGL & Invesco DB Gold Fund & $\begin{array}{c}\text { золото на фьючерс- } \\
\text { ной основе }\end{array}$ & 0,75 & 4,52 & $-1,27$ \\
\hline 8 & ZSL & ProShares UltraShort Silver & $\begin{array}{c}\text { серебро на фьючерс- } \\
\text { ной основе }\end{array}$ & 1,62 & 17,02 & $-4,3$ \\
\hline 9 & GLTR & $\begin{array}{c}\text { Aberdeen Standard Physical Precious } \\
\text { Metals Basket Shares ETF }\end{array}$ & $\begin{array}{c}\text { корзина драгоценных } \\
\text { металлов (фьючерсы) }\end{array}$ & 0,6 & 5,48 & $-4,71$ \\
\hline 10 & DGZ & DB Gold Short ETN & $\begin{array}{c}\text { золото на фьючерс- } \\
\text { ной основе }\end{array}$ & 0,75 & $-2,7$ & $-6,74$ \\
\hline
\end{tabular}

Источник: [4] 
оферты, никак не подкреплялись физическими объемами металла, находящемся в хранилищах;

- зависимость дохода от действий управляющего фонда.

Таким образом, ETF представляют собой хорошую возможность для инвестора диверсифицировать свой портфель, не приобретая при этом множество активов. Однако при инвести- ровании в ETF инвестору придется просчитывать гораздо большее количество факторов и быть более внимательным, так как ETF по драгоценным металлам очень и очень много и все они отличаются по степени риска, доходности и издержек. Такой способ подойдет более опытным инвесторам, уже сталкивающимся с инвестициями в биржевые инструменты.

\section{Библиографический список}

1. Информационно-аналитический портал «Все о биржевых и индексных фондах» [Электронный ресурс].Электрон. дан.- Режим доступа: http://etfunds.ru/

2. Информационно-аналитический портал Investing.com [Электронный ресурс]. - Электрон. дан. - Режим доступа: https://ru.investing.com/

3. Официальный сайт группы «Московская Биржа» [Электронный доступ].- Электрон. дан.- Режим доступа: https://www.moex.com/

4. Official web-site of ETF Report URL: https://www.etf.com/ 